\title{
PHLPP: a putative cellular target during insulin resistance and type 2 diabetes
}

\author{
Alpana Mathur,2, Vivek Kumar Pandey ${ }^{1,3}$ and Poonam Kakkar1,2,3 \\ ${ }^{1}$ Herbal Research Laboratory, CSIR-Indian Institute of Toxicology Research, Lucknow, India \\ 2Babu Banarasi Das University, BBD City, Lucknow, India \\ ${ }^{3}$ Academy of Scientific and Innovative Research, CSIR-IITR, Lucknow, India
}

Correspondence should be addressed to P Kakkar

Email

pkakkar@iitr.res.in

\begin{abstract}
Progressive research in the past decade converges to the impact of PHLPP in regulating the cellular metabolism through PI3K/AKT inhibition. Aberrations in PKB/AKT signaling coordinates with impaired insulin secretion and insulin resistance, identified during T2D, obesity and cardiovascular disorders which brings in the relevance of PHLPPs in the metabolic paradigm. In this review, we discuss the impact of PHLPP isoforms in insulin signaling and its associated cellular events including mitochondrial dysfunction, DNA damage, autophagy and cell death. The article highlights the plausible molecular targets that share the role during insulin-resistant states, whose understanding can be extended into treatment responses to facilitate targeted drug discovery for T2D and allied metabolic syndromes.
\end{abstract}

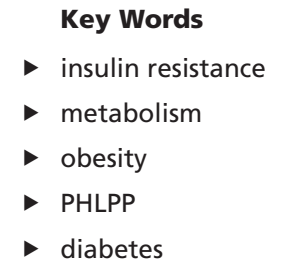

Journal of Endocrinology (2017) 233, R185-R198

\section{Background}

Type 2 diabetes (T2D), obesity and allied disorders are posing serious health problems that are reaching epidemic proportions worldwide (Nanditha et al. 2016). Insulin resistance, a key feature of T2D and obesity, subdues the efficiency of its target tissues for glucose uptake and its metabolism in response to insulin signaling (Hanssen et al. 2015). Inactivation of the receptor responses (signaling molecules) has been reported as the underlying cause responsible for impaired insulin action (Copps \& White 2012). Newton's group first claimed the identification of a protein phosphatase, PHLPP, while searching for a mechanism of AKT dephosphorylation and signal termination (Newton et al. 2005). PHLPP directly dephosphorylates AKT at its hydrophobic motif (Ser473). AKT is a crucial player to execute intracellular responses post IRS-1 (insulin receptor substrate-1) phosphorylation (Machado-Neto et al. 2011, Warfel \& Newton 2012).
Overexpression of PHLPP isoforms is associated with several human diseases, including cancer, obesity, cardiovascular disorders and diabetes (Miyamoto et al. 2010, Andreozzi et al. 2011). However, limited studies on its role in the diabetic milieu underscore the medical relevance of PHLPPs and make it an attractive drug target for the treatment during insulin-resistant states.

The PHLPP family comprises three isozymes, the alternatively spliced PHLPP $1 \alpha$ and PHLPP $1 \beta$ (also referred to as suprachiasmatic nucleus circadian oscillatory protein (SCOP)) and PHLPP2, a separate gene product (Shimizu et al. 2003). PHLPPs substrate selectivity differs for specific AKT isoforms. PHLPP1 preferentially dephosphorylates AKT2, while PHLPP2 targets AKT1; however, the selectivity is probably tissue dependent and might also vary with the cellular state (Gao et al. 2005, Brognard et al. 2007). In a study by Andreozzi 


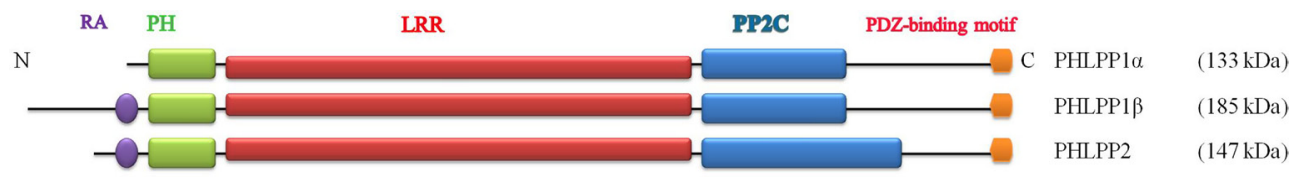

Figure 1

The three PHLPP isoforms share a common N terminal PH domain (pleckstrin homology), a series of leucine-rich repeats (LRR), a protein phosphatase domain and a PDZ binding motif (post synaptic density protein (PSD95), Drosophila disc large tumor suppressor (DlgA) and zonula occludens-1 protein (zo-1) binding motif toward the $\mathrm{C}$ terminal. The splice variant PHLPP1 $\beta$ has an additional Ras association domain at its $\mathrm{N}$-terminus. Its structure resembles with that of PHLPP2. A full colour version of this figure is available at http://dx.doi.org/10.1530/JOE-17-0081.

and coworkers (Andreozzi et al. 2011), impaired insulin action was associated with higher PHLPP1 expression in the adipose and skeletal muscle tissues of obese patients. Further, liver and skeletal muscle cells transfected with recombinant PHLPP1 demonstrated decreased GSK-3 $\alpha / \beta$ phosphorylation and glycogen synthesis confirming the fact that changes in PHLPP1 abundance contribute to insulin resistance (Aviv \& Kirshenbaum 2010). Recently proposed mechanism suggests that insulin suppresses PHLPP1 to enhance AKT activation but as lower insulin effectiveness prevails in aged hearts, it fails to decrease PHLPP1 during myocardial infarction/reperfusion, subsequently limiting AKT activity and cardioprotection (Xing et al. 2016). One of the studies in obese mice confirmed that increased PHLPP1 expression allows pronounced AKT/PHLPP1 interaction which weakens the insulin response (Caricilli et al. 2012) and hypothalamic silencing of PHLPP1 lead to greater weight loss and reduction in adiposity with improved insulin signaling in obese mice (Caricilli et al. 2012). Altogether, the findings indicate that PHLPP1 isoform plays an important role in insulin signaling, therefore, specific therapies that inhibit this isoform in diabetes may be particularly useful; however, a firm demonstration is required to clarify the substrate selectivity of PHLPP isoforms in the diabetic paradigm. Studies suggest that the mechanisms responsible for the pathogenesis associated to insulin resistance may be arrested via selective PHLPP inhibitors (Sierecki et al. 2010, Hribal et al. 2016). The clinical significance of PHLPP and its downstream factors underpin the need to fully understand the structure and regulation of PHLPPs such that therapies could be targeted against it.

\section{PHLPP: structure and expression}

PH domain leucine-rich repeat protein phosphatases have three isozymes, with the alternatively spliced PHLPP1 $\alpha$, PHLPP1 $\beta$ and PHLPP2. PHLPP1 $\alpha$ comprises 1205 amino acids and PHLPP $1 \beta$ comprises 1717 amino acids both being products of the same gene, positioned at chromosome 18q21.33. PHLPP2 (PHLPPL), a 1323 amino acid protein, is encoded by a different gene located at chromosome 16q22.3 (Brognard \& Newton 2008). The structural unit of PHLPP comprises an N-terminal PH domain, leucinerich repeat region, a phosphatase domain (PP2C) and a C-terminal PDZ binding motif (Fig. 1). The PHLPP isoform $1 \alpha$ lacks an additional N-terminal Ras Association domain. The multiple regulatory domains allow it to control several effector molecules through mechanisms other than the phosphatase activity. Although ubiquitous expression has been observed with the PHLPP isoforms, their levels vary within different tissues, being most abundant in brain. They show broad intracellular localization associated with its scaffolding proteins in the cytoplasm, nucleus, plasma membrane and mitochondria (Mendoza \& Blenis 2007, Molina et al. 2012).

The mechanistic details of its intrinsic catalytic activity have been less documented. However, a recent report highlights insight into its catalytic domain through screening selective inhibitors (Sierecki et al. 2010, Jackson et al. 2013). The phosphatase domain of PHLPP belongs to the type $2 \mathrm{C}$ phosphatase (PP2C) subclass of the Protein Phosphatase Metal-dependent (PPM) family of Ser/ Thr phosphatases. PHLPP differs from other PP2C members in its metal requirement where the enzyme requires $\mathrm{Mn}^{2+}$ to initiate the activity rather than $\mathrm{Mg}^{2+}$. The catalytic PP2C domain is structurally a sandwich between two antiparallel $\beta$-sheets, flanked by two antiparallel $\alpha$-helices. Its complete structural characterization has been reviewed earlier (Sierecki \& Newton 2014). Importantly, four Asp residues and a non-conserved Glu comprise the catalytic core where the key residues for the catalytic activity in the PP2C domain include aspartate 806, glutamate 989 and aspartate 1024 (Brognard \& Newton 2008). Recent findings have revealed two important positively charged residues, an Arg and a His, where first one allows positioning the phosphate group correctly and the latter acts as a general acid for catalysis. PHLPPs dephosphorylate synthetic and peptidic substrates with kinetics dependent entirely on

Published by Bioscientifica Ltd. 
the substrate and the expression systems. Inhibitors of this enzyme increased phosphorylation of AKT, PKC and its downstream substrates to prevent apoptosis. Studies are required to identify the endogenous PHLPP regulators. Both PHLPP isozymes have an abundance of predicted phosphorylation sites and indeed, it has been suggested that factors downstream of the insulin receptor may modulate PHLPP activity (O'Neill et al. 2013).

\section{PHLPP mediates cellular events leading to diabetic risks}

To date, AKT, PKC, S6K1, Raf (Li et al. 2014) and MST1 (Warfarel et al. 2011) have been reported as the direct substrates to be negatively regulated by PHLPP, thereby affecting cell growth and proliferation. Both the PHLPP isoforms share the ability to dephosphorylate their substrates but modulate a distinct subset of signaling events downstream of AKT, implicating non-overlapping functions of the two isoforms ( $\mathrm{O}^{\prime}$ Neill et al. 2013). Repressions of these vital signaling proteins by PHLPP, 'switch off' the action and act as an important player for specific and dynamic regulation in mammalian cells. Overexpression/genetic mutation in the PI3K gene or disturbance in its regulatory components leads to insulin resistance (Schultze et al. 2012, Winnay et al. 2016). The alterations brought about in PKC, GSK3 $\beta$ and their downstream targets correspond to the pathogenicity observed during diabetes including oxidative stress (Gerber \& Rutter 2017), mitochondrial dysfunction (Peiris et al. 2016), impaired glucose metabolism (Aguayo et al. 2016), aberrant autophagy (Quan et al. 2012) and cell death (Hwang et al. 2015). Interestingly, diabetes marks the impairment of mTOR/PHLPP axis in adjusting AKT responses; however, its action remains poorly understood in the context of diabetes (Kim et al. 2016). Therefore, the concerted molecular understandings of PHLPP shall allow predicting several novel interactions and targets that have not yet been identified during diabetes. Associated cellular metabolic disturbances further mark the role of PHLPP in the progression of diabetes as described below.

\section{PHLPP alters mitochondrial function during insulin-resistant states}

Compromised mitochondrial function is apparent during diabetes (Fetterman et al. 2016). Insulin deficiency (Type I DM) and insulin resistance (Type II DM) are associated with overactive oxidative phosphorylation through inadequate insulin effect on mitochondria leading to ROS production (Sakai et al. 2003). Insulin plays an important role in the rapid modulation of myocardial respiration through mitochondrial AKT1 (Yang et al. 2013). Insulin-mediated AKT1 translocation and activation in mitochondria represents a signaling mechanism linking extracellular fuel supply and hormonal response to coordinate bioenergetic supply and demand in the cellular system. Thus, an interesting signaling pathway links insulin signaling to mitochondria through translocation of AKT. Hexokinase II (HK-II), a glycolytic enzyme, is known to translocate to the mitochondria (Roberts \& Miyamoto 2015) and its deficiency contributes to the altered sensitivity of diabetes to cardiovascular disorders. PHLPP behaves as a novel regulator of glucose metabolism by negatively regulating the AKT and S6K kinase activity, which are known molecular players of glucose metabolism (Xiong et al. 2016). In another study, retinal cells indicated that AKT activation is light dependent where light-induced activation of IR/PI3K/AKT signaling leads to mitochondrial translocation of HK-II. Moreover, the process was enhanced by GSK-3 $\beta$ inhibition and was regulated by PHLPP1 $\beta$ to confer cellular protection by apoptosis inhibition (Rajala et al. 2013). Therefore, indirect interaction of PHLPP1 $\beta$ with HK-II suggests its potential role in mitochondrial homeostasis.

Activated AKT translocates to the mitochondria and enhances mitochondrial HK-II binding by phophorylation at Thr 473 (Roberts et al. 2013). Phosphorylation-mediated regulation of mitochondrial HK-II (Roberts \& Miyamoto 2015) is therefore a critical step to confer protection by AKT. Thus, the fact of highly diminished mitochondrial activity during diabetes may be attributed to the gain in PHLPP function and consequent inhibition of mitochondrial HK-II phosphorylation by suppressed AKT action.

In adipocytes, AKT1 and AKT2 show differential translocation to the mitochondria under insulin stimulation during normal cell conditions. Although some p-AKT1 remain in the cytosol after insulin stimulation and never translocates, the majority of p-AKT1 shift to the mitochondria and nucleus (Yang et al. 2009). In the isoform-specific knockout model, AKT1 and AKT2 potentially serve as alternative signaling pathways for each other. Primarily AKT1 relays insulin signaling to mitochondria and modulates mitochondrial complex $\mathrm{V}$ (ATP synthase) activity. Inhibition of AKT blocks insulinstimulated p-AKT translocation and leads to blunted activation of complex V (Senapedis et al. 2011). Also, the perturbed energy balance observed during diabetes is due

Published by Bioscientifica Ltd. 
to loss of uncoupling protein 5 (UCP5) and upregulation of uncoupling protein 3 (UCP3). Thus, inhibition of PHLPP could prevent the energy drain of cells through complex $\mathrm{V}$ activation, thereby preventing mitochondrial integrity through AKT translocation. Thus, the integration of energy balance and mitochondrial function links to PHLPP through AKT action. Further studies are required to validate the role of PHLPP isoforms in regulating the mitochondrial activity during diabetes.

\section{Potential role of PHLPP in proteotoxicity: modulation of unfolded protein response (UPR)}

Endoplasmic reticulum stress has been marked in conjunction with the severity of diabetes leading to excessive deposition of misfolded proteins in the ER compartment. The UPR sensor proteins like IRE1, ATF6 and PERK get activated to correct the improper protein maturation in the ER (Liu et al. 2015). Misfolded proteins in the ER induce the cell death response through PERKmediated phosphorylation of eIF $2 \alpha$ and TRB3, a target gene of CHOP, to promote apoptosis (Guo et al. 2015). Moreover, the ER stress factors XBP1, ATF4 and ATF6 rely upon SIRT1 induction for their activation. The PI3K-AKT-
GSK3 $\beta$ signaling pathway is required for SIRT1 induction by ER stress (Koga et al. 2015). Recent reports showed that SIRT1 deacetylates XBP1 and inhibits its transcriptional activity to promote ER stress-induced apoptosis and SIRT1 suppresses the PERK-eIF2 $\alpha$-dependent translational inhibition in mammals. SIRT1, thus, has been known to be a negative regulator for ER stress response. However, compared with the effect of SIRT1 on ER stress response, the effect of ER stress on SIRT1 is less studied. The role of PHLPP may be manifested in the regulation of ER factors through Sirt1 via AKT inhibition. Another ER stressinducible protein, TRB3, is found upregulated during diabetes (Das et al. 2014). It is an intracellular pseudokinase that modifies cellular survival and metabolism through AKT inhibition. CHOP induces TRB3 expression during ER stress-induced cell death. It downregulates its own induction through CHOP/ATF4 axis (Ohoka et al. 2005), and knockdown of TRB3 exerts a protective effect during diabetes by improving insulin resistance and hepatic glucose output (Marinho et al. 2015). Knowledge from recent findings indicate that TRB3 binds to mTORC2 during diabetes and prevents it from phosphorylating AKT at Ser 473, thereby contributing to increased inflammation and desensitized insulin signaling (Borsting et al. 2014).

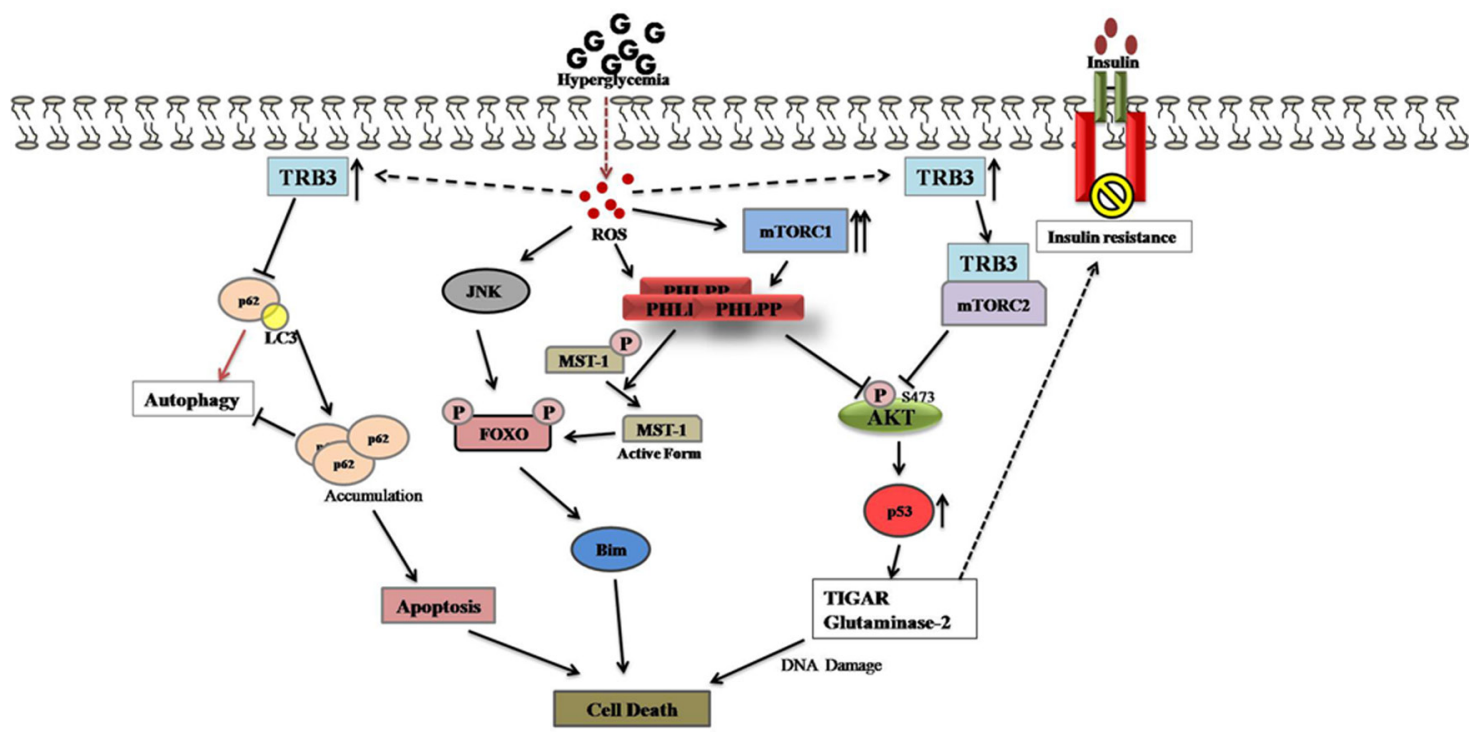

Figure 2

Regulation of cell death by PHLPP involves parallel action of several factors. Absence of insulin or growth factors promotes phosphorylation of FOXO transcription factors by AKT, JNK and MST1 at conserved sites that allows causing cell death through bim induction. PHLPP dephosphorylates MST1 that activates FOXO and induces cell death progression during hyperglycemic stress. ROS-mediated TRB3 induction sequesters mTORC2 from phosphorylating AKT and thereby inhibiting its signaling. Simultaneously, hyperactivation of mTORC1 allows enhanced PHLPP1/2 expression leading to total AKT inhibition and insulin resistance. TRB3 further prevents p62/LC3 association, impeding autophagy. Further, p53 worsens insulin signaling by modulating the gluco-metabolic genes (TIGAR and glutaminase 2) along with the inhibition of mTORC2 and IGF-1/AKT axis through indirect intervention of PTEN, TSC1/2, SESTRIN and PTEN. Overall, the figure describes the putative mechanisms that promote apoptosis during insulin resistant states. A full colour version of this figure is available at http://dx.doi.org/10.1530/JOE-17-0081. 
Simultaneously, the increased metabolic load causes hyperactivation of mTORC1 in $\beta$ cells. This relates to the translational control of mTORC1 on PHLPP leading to its enhanced synthesis (Liu et al. 2011). No direct evidence implicates TRB3 interaction with PHLPP. However, the overall outcome upon the cell functions could be a synergistic effect of mTOR/PHLPP/TRB3 axis in modulating AKT through checking its phosphorylation by mTORC2 inhibition and concurrent overexpression of PHLPP via mTORC1 (Fig. 2).

\section{PHLPP/mTORC2 regulates the interplay of autophagy to apoptosis switchover}

Cellular homeostasis requires a delicate balance between macromolecules/organellesynthesis and their degradation. During diabetes, this balance is hampered and leads to cell death (Fig. 3). Hur and coworkers (Hur et al. 2010) reported that $\beta$-cell mass decreases in autophagy-deficient mice along with bulk accumulation of ubiquitinated proteins, dysfunctional mitochondria and distended ER. In another study, autophagy is highlighted as a decisive factor in the progression from obesity to diabetes where $\beta$-cell-specific ATG7 null mice showed hyperglycemia and hyperinsulinemia due to inappropriate response to obesity-induced ER stress (Quan et al. 2012). Therefore, in addition to $\beta$-cell homeostasis, dysregulated autophagy is possibly involved in diverse aspects of the pathogenesis of diabetes. A vital factor for autophagic regulation is mTOR. However, there lies an mTOR-independent mechanism, which depends upon BECLIN1 phosphorylation by AKT (Wang et al. 2012). PHLPP might play a significant role in governing the shift from autophagy to apoptosis through regulation of beclin-1 phosphorylation by checking AKT phosphorylation. Indirect evidence exists for this plausible molecular mechanism (Fig. 3). However, the functional significance of PHLPP1/2 in regulating autophagic responses is yet to be examined.

Chaperone-mediated autophagy (CMA) contributes during pathological situations where critical protein overproduction or its degradation decides the molecular homeostasis (Tasset \& Cuervo 2016). In a study, CMA was found to be under positive control of PHLPP1. The mTORC2/PHLPP1 kinase-phosphatase pair modulates lysosomal AKT levels and hence the CMA activity is regulated by a distinct control of the dynamics of assembly and disassembly of the CMA translocation complex at the lysosomal membrane. Thus, the lysosomal mTORC2/ PHLPP1/AKT axis could become a target to restore CMA dysfunction during diabetes (Arias et al. 2015).

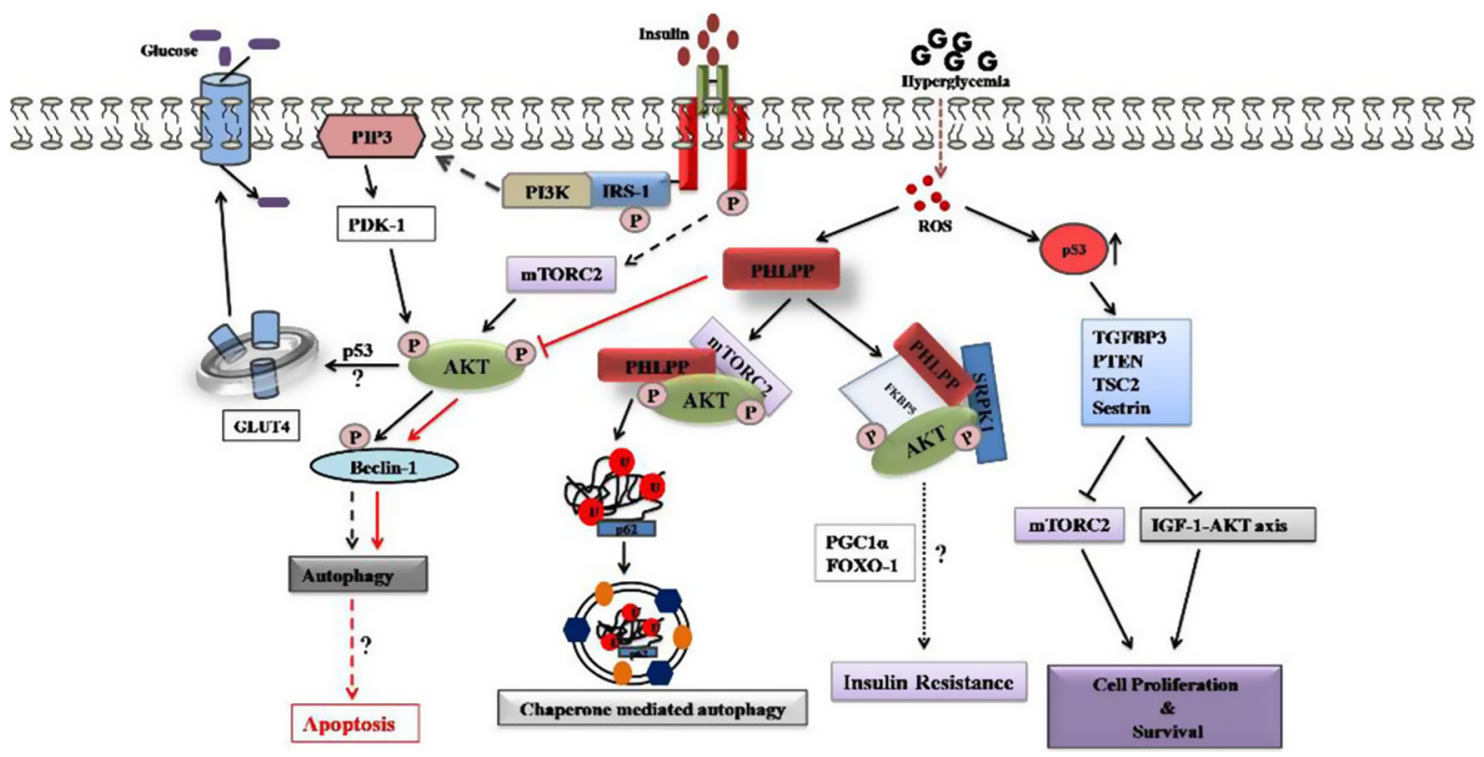

Figure 3

The adaptor proteins FKBP51 and SRPK1 recruit PHLPP to elicit AKT dephosphorylation at S473 and allow the progression of insulin resistance through molecular intervention of FOXOs and PGC-1 $\alpha$ with PHLPP. However, the exact mechanism remains incompletely understood. Aberrant autophagy, observed during hyperglycemic states, is regulated by PHLPP by checking beclin-1 phosphorylation via AKT inhibition and thereby instigating the cell to adopt apoptotic cell death. Further, the mTORC2/PHLPP/AKT complex controls chaperone-mediated autophagy regulating cell death. Excessive ROS induces p53 induction whose dynamic control over the glucose metabolic pathway and cell survival signaling apoptosis through inhibition of the IGF-AKT-mTORC2 axis. A full colour version of this figure is available at http://dx.doi.org/10.1530/JOE-17-0081. 


\section{Essential role of PHLPP in fuel metabolism}

All 'sweet' metabolism turns around the central PKB/ AKT pathway, so PHLPP being an AKT inhibitor regulates indirectly the factors that are directly associated with AKT phosphorylation. An important fact lies behind AKT substrate regulation, where all its substrates are not activated/inhibited under similar propensity of AKT phosphorylation. The thresholds in p-AKT amplitude determine the multitude downstream signaling during various stress conditions. So, it is very important to understand that all molecular cross-talks are not direct and are of the same intensity. All cellular actions are very precisely regulated according to the milieu inside the cell to provide best possible outcome for survival.

An important AKT substrate, GSK3 $\beta$, is a Ser/Thr kinase known to play a predominant role in glycogen synthesis. AKT phosphorylates both the GSK isoforms on serine residue GSK3 $\beta$ (Ser9) and GSK3 $\alpha$ (Ser21). Its activity leads to glycogen synthesis. GSK3 $\beta$ is essentially considered as a potential drug target for T2D because it has been observed that its inhibition improves pathogenesis incurred due to insulin resistance (Li et al. 2015). Furthermore, a report suggests that bTrCPmediated degradation requires phosphorylation by both casein kinase I and GSK-3 $\beta$. This 'activation' signaling process is suppressed by phosphatidylinositol 3-kinase/ AKT pathway (Li et al. 2009).

During T2D, loss of pancreatic $\beta$-cell mass leads to defects in insulin secretion. Alterations have been observed in the AKT/GSK3 $\beta$ signaling pathway, which cause $\beta$-cell dysfunction by substantially reducing the levels of PDX1 and CYCLIN D1 proteins (Humphrey et al. 2010). PDX1 activates GLUT2 and glucokinase genes in the pancreas and affects glucose sensing by inducing the expression of genes of the mitochondrial metabolic pathway post AKT induction (Humphrey et al. 2010). So, direct pharmacologic inhibition of GSK3 $\beta$ increases PDX1 protein stability thereby mediating the effects of glucose via the AKT-GSK3 $\beta$ axis. Important aspect of GSK3 $\beta$ activity involves phosphorylation of insulin receptor substrate (IRS)-1 at Ser332, following priming at Ser336, thereby promoting its degradation. So, the loss of key molecule of insulin signaling due to aberrant activation of GSK3 $\beta$ reduces the insulin signaling capacity of the cell resulting in glucose intolerance and insulinresistant conditions. Consistent with the molecular predictions, modulation in the PHLPP levels enhances GSK3 $\beta$ activation, so a reversal in this process by either direct GSK3 $\beta$ inhibition or through PHLPP shall reduce hyperglycemia and insulin resistance.

\section{PHLPP and energy responses}

Evidently, physiological stimuli like starvation, amino acid levels and glucose levels are known factors to affect mTOR activity. The expression of both the PHLPP isoforms is regulated by mTOR-dependent protein translation (Liu et al. 2011). Pharmacological or genetic inhibition of mTOR activity has shown to reduce PHLPP expression via S6K and 4E-BP1. S6K1 (also named p70 $\mathrm{S} 6 \mathrm{~K})$, a member in the AGC kinase, has been identified as a novel substrate of PHLPP, proving the diverse functional role of PHLPP in regulating protein translation and cell growth as well. In response to growth factor stimulation, mTOR phosphorylates S6K1 at T389 followed by PDK-1, which phosphorylates it at T229. S6K1 in its inactivated state is associated with eukaryotic initiation factor 3 (eIF3) in the translation initiation complex and gets rapidly released upon mTOR-mediated phosphorylation. Taken together, the loss of PHLPP expression activates the S6Kdependent negative feedback loop, and PHLPP behaves as a novel player involved in regulating protein translation initiation and cell size via direct dephosphorylation of S6K1 (Liu et al. 2011).

\section{PHLPP and redox response}

Nrf2 has largely been explored as a major detox factor; however, it also has an important role in glucose metabolic programming. Reports indicate the involvement of $\mathrm{Nrf} 2$ in regulating enzymes of the non-oxidative arm of PP pathway i.e. TKT (transketolase) and TALDO (transaldolase) (Heiss et al. 2013). Livers of Nrf2 null mice are reported to decrease expression of G6PD, PGD, IDH1 and ME1 enzymes involved in NADPH synthesis (Holmström et al. 2013). Thus, Nrf2 modulates glucose and glutamine metabolism by directly upregulating the transcription of NADPH-generating enzyme genes. Nrf2 impart these actions through its translocation into the nucleus and there upon binding to its responsive elements. A delayed mechanism response involves GSK3 $\beta$ to regulate nuclear import and stabilization of Nrf2 (Jain \& Jaiswal 2007, Shang et al. 2015). GSK3 $\beta$ phosphorylates Fyn kinase, a Src family tyrosine kinase, at unknown residues. This active p-Fyn kinase enters the nucleus and phosphorylates Nrf2 at tyrosine 568 resulting in the nuclear export and degradation of Nrf2 
(Jain \& Jaiswal 2007, Rizvi et al. 2014). PHLPP governs GSK3 $\beta$ through AKT and thus checks the Nrf2 inductive response during diabetes. Thus, PHLPP seems an upstream regulator of redox and glucose signaling. Its endogenous regulation and impact upon crucial signaling factors need more understanding in the hyperglycemic state.

\section{PHLPP dephosphorylate MST1 to trigger apoptosis during T2D}

Mammalian Sterile 20-like kinases (Msts) are serine threonine kinase. The two isoforms MST1 and MST2 are expressed ubiquitously and regulate multiple cellular processes including morphogenesis, proliferation, stress response and apoptosis (Song et al. 2010). During diabetes, excessive apoptosis via MST1 in pancreatic $\beta$ cells is responsible for diminished insulin production (Ardestani et al. 2014). PHLPP also catalyzes the dephosphorylation of the inhibitory site on the kinase MST1. Its subsequent dephosphorylation by PHLPP upon its autoinhibitory site (Thr387) activates MST1, leading to the activation of the pro-apoptotic MAPK pathway (Qiao et al. 2010). This same T387 site is phosphorylated by AKT. Therefore, PHLPP, AKT and MST1 together form an auto inhibitory triangle, which maintains a fine balance of apoptosis and proliferation (Qiao et al. 2010).

Moreover, a neuronal-based study reported the activation of MST1, where Forkhead boxO3 (FOXO3) phosphorylation promotes cell death through induction of BIM, a pro-apoptotic gene (Xiao et al. 2011). Furthermore, a study demonstrated the role of a tyrosine kinase, c-Abl, whose interaction with MST1 promotes cellular apoptosis via Cdk5/GSK3 $\beta$ activation. The study implicates the role of oxidative stress in mediating the interaction of c-Abl with MST-1, which is enhanced and leads to cell death through FOXO3A. FOXO3A activation has also been observed during diabetic nephropathy where its phosphorylation by TGF- $\beta$ leads to renal fibrosis (Kato et al. 2006). Therefore, these cross links highlight the upstream regulatory mechanism of MST1 via PHLPP, whose inhibition could be employed as a management therapy during diabetes.

\section{Targeting the critical PHLPP-AKT interaction: role of scaffolding proteins}

The proximity between PHLPP and AKT has been reported to be assisted by scaffolding proteins such as FKBP5
(Pei et al. 2009), NHER1 and SRPK1 (Molina et al. 2012) (Fig. 3). Different cellular states modulate these proteins so as to ensure the association between PHLPP and AKT. The immunophilin FKBP5 acts as scaffolding protein for AKT and PHLPP (Molina et al. 2012). Enhanced hypothalamic levels of FKBP5 are associated with increased body weight. Therefore, FKBP5 represents a novel target in metabolic regulation. It has been reported that ATP or certain concentrations of statins activate PHLPP isoforms along with other phosphatases and regulate signaling patterns (Pereira et al. 2014). On a deeper note, the activation of phosphatases depends upon the factors that regulate cell cycle. So, higher FKBP5 gene expression is observed in adipose tissue and is associated with reduced insulin effects on glucose uptake (Pereira et al. 2014). Furthermore, its gene expression in subcutaneous adipose tissue positively correlates with serum insulin, adipocyte diameter and negatively with plasma HDLcholesterol, thereby implicating its possible potential role in insulin resistance. Higher FKBP5 expression would allow more binding affinity for PHLPP with AKT, leading to diminished insulin signaling. Moreover, several FKBP5 SNPs have been found to be associated with T2D and diabetes-related phenotypes in large population-based samples (Pereira et al. 2014).

Another scaffolding protein, SRPK1, is overexpressed in cancerous cells where it sequesters PHLPP1 and induces constitutive AKT activation. However, its aberrant expression, either under- or overexpression, induces constitutive AKT activation (Wang et al. 2014). This notion opens many questions to identify the basis of the mechanisms by which SRPKs can regulate PHLPP-AKT interaction. Also, PHLPPs have shown to modulate ERK signaling, which has been implicated in the development of insulin resistance associated with obesity and T2D (Li et al. 2014), while insignificant effects on ERK phosphorylation are observed upon SRPK1 inactivation. So, the precise nature in this background remains incompletely understood. More translatory approach is required to ascertain as to which factor specifically affect PHLPP/AKT association during diabetes. Similarly, consistent with the fact that PHLPP1 and PHLPP2 show biased specificity toward AKT1, AKT2 and AKT3 isoforms (Brognard \& Newton 2008), the role of this specificity in SRPK1 inactivation or overexpression is unknown. The interaction of PTEN, a widely known negative regulator of insulin/PI3K signaling with $\mathrm{Na}^{+} / \mathrm{H}^{+}$ exchanger regulatory factor 1/ezrin-radixin-moesin (ERM)-binding phosphoprotein 50 (NHERF1/EBP50), adds more precision in AKT regulation. Mutations in

Published by Bioscientifica Ltd. 
PTEN have been reported as a cause for insulin resistance and obesity (Pal et al. 2013). NHERF1 binds directly to PTEN (He et al. 2012) and PHLPP1/2 via PDZ domain and scaffolds ternary complexes at the membrane to suppress the activation of the PI3K-AKT pathway (Molina et al. 2012). Reduced levels of NHERF1 have been observed during diabetic diarrhea (He et al. 2015) along with its mobilization from the plasma membrane into the cytoplasm, leading to hyperactivation of PHLPP1/2 and subsequent PTEN-induced AKT inactivation (Molina et al. 2012). Importantly, complex formation with NHERF1 appears essential to regulate cell survival effects as NHERF1 loss might influence cell growth by deregulation of PHLPP proteins. Thus, there is a complex inhibitory network function that relies on either independent or synergistic molecular interactions via the scaffolding proteins to arrest diabetes progression. The challenge remains to explore the specific mechanisms that influence PHLPP activity during diabetes.

\section{Degradation of PHLPP: a complex event}

Ubiquitination, a post-translational modification, is recognized by the proteasomal system as a signal to degrade proteins. Loss of this signaling cascade or its over activation both lead to deleterious conditions. Like any other eukaryotic protein, PHLPP also undergoes degradation via $26 \mathrm{~S}$ proteasomal pathway. Insulinresistant conditions are marked with altered proteasomal degradation (Aghdam et al. 2013). Overexpression of the deubiquitinating proteins poses serious threat to the cells via AKT inhibition. So far, very limited mechanisms have been identified for the regulation of PHLPP during hyperglycemia. Its regulation at transcript level is completely unknown. The machinery required to maintain PHLPP protein levels works in concert with $\mathrm{bTrCP}$ and specific deubiquitinases such that a balance is maintained upon PHLPP function. Pathological states create an imbalance and hamper cell survival (Fig. 4).

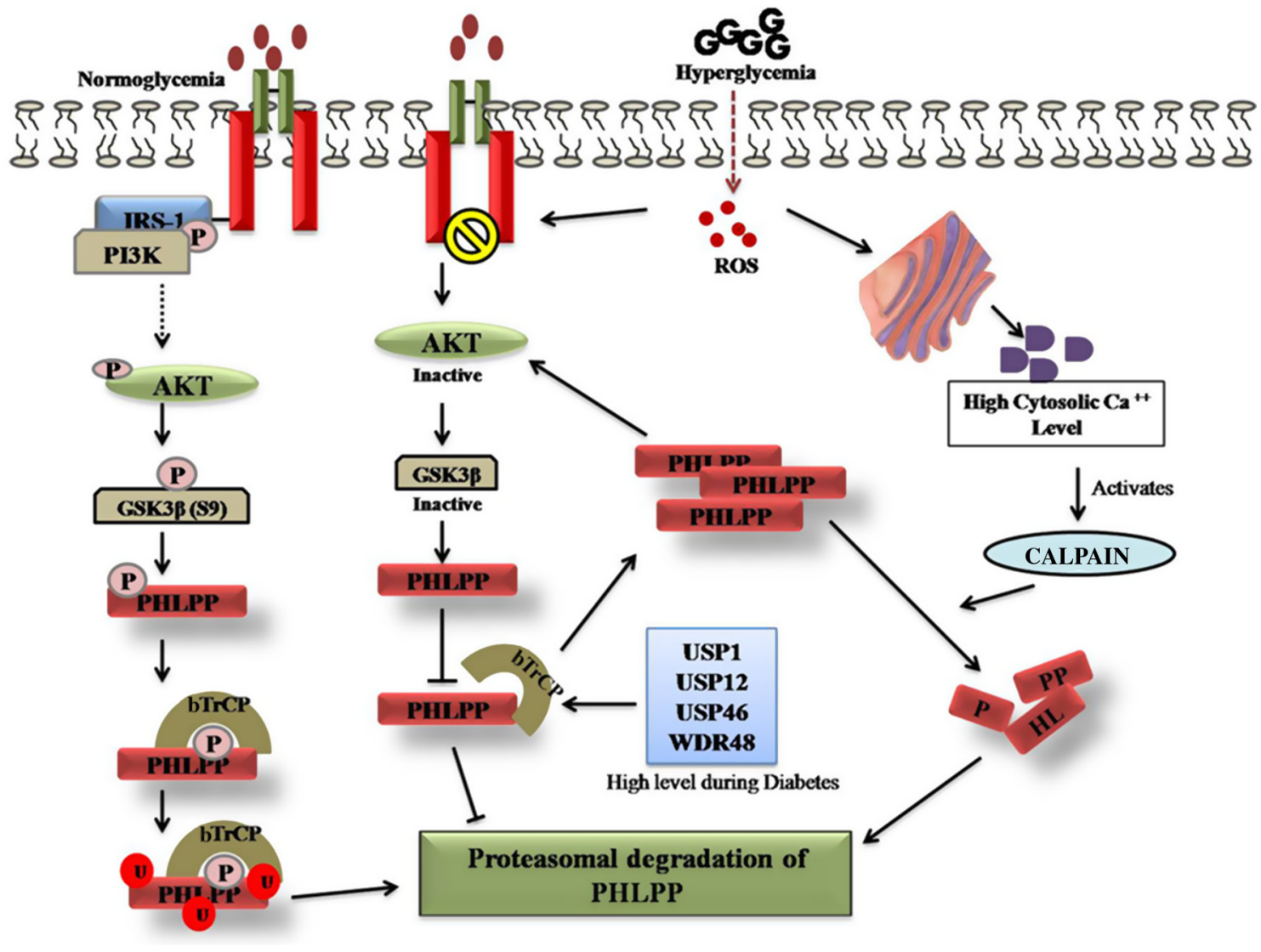

Figure 4

During normoglycemic conditions, activated AKT allows bTrCP-mediated PHLPP ubiquitination. Phosphorylation of PHLPP1 by casein kinase 1 and GSK3 $\beta$ in the residues residing into the PP2C domain generates a phosphodegron motif that promotes PHLPP degradation. During hyperglycemia, activated GSK3 $\beta$ prevents phosphorylation of PHLPP1 thereby restricts its degradation leading to its constitutive stability. ER stress and mitochondrial dysfunction allow leaky release of calcium ions which promotes activation yet does not degrade PHLPP during hyperglycemia. Coexisting deubiquitinases further fine tune PHLPP degradation. Hence, several concomitant processes run to regulate PHLPP. 
PHLPP1 is identified as a proteolytic target of bTrCP. The degradation process of PHLPP1 relies on casein kinaseI(CK1) and GSK3 $\beta$-mediated phosphorylation where activation of AKT negatively regulates PHLPP1 turnover (Li et al. 2009). Binding of bTrCP (an E3 ubiquitin ligase) to PHLPP1 requires GSK3 $\beta$-dependent phosphorylation on PHLPP1. Interestingly, during diabetes, inhibition in PI3K/AKT signaling prevents docking of bTrCP to PHLPP1 leading to sustained activation of PHLPP (Warfarel et al. 2011). A very recent study identified that insulin regulates PHLPP1 degradation in cardiomyocytes (Xing et al. 2016). Low insulin effectiveness prevails in aged hearts, which subsequently fail to decrease PHLPP1 during $\mathrm{MI} / \mathrm{R}$ (myocardial ischemia/reperfusion) and thereby limits AKT activity and cardioprotection. It was observed that insulin treatment of the aged heart could enhance the binding between PHLPP1 and bTrCP to target for ubiquitin-dependent degradation. Altogether, this new mechanism defines insulin-mediated suppression of PHLPP1 to enhance AKT activation and therefore presents PHLPP1 as a promising therapeutic target during insulin resistance.

\section{CALPAINS}

CALPAINS (calcium-dependent cysteine proteases), are proteins capable of degrading PHLPP and participate in insulin secretion and action. Increases in intracellular calcium levels are reported to reduce PHLPP1 $\beta$ levels through CALPAIN-mediated degradation (Smith et al. 2012). Literature highlights the involvement of CALPAIN 10 during diabetes (Bodhini et al. 2011). Further, CALPAINS are found to be responsible for the disturbance in the mitochondrial homeostasis during diabetes, and CALPAIN 10 is the only member of its family to reside in the mitochondria (Smith et al. 2012). Lowered levels of CALPAIN 10 have been observed during STZ-induced diabetic nephropathy resulting in renal cell apoptosis and organ failure through the accumulation of mitochondrial CALPAIN 10 substrates (Smith et al. 2012). CALPAIN 1 is also associated with mitochondrial ROS generation and oxidative damage. Moreover, it regulates ATP synthase- $\alpha$ (ATP5A1) protein and ATP synthase activity, whose loss in activity promotes diabetic cardiomyopathy (Ni et al. 2016). However, the role and functional significance of CALPAINS in diabetic complications has not been fully characterized. Specific inhibitor of CALPAINS may be employed to avert the diabetic progression. However, these inhibitors may cause sustained PHLPP activation. At the same time a possibility behind this contradictory fact may be the more significant proteasomal activity via bTrCP over CALPAIN's action in regulating PHLPP stability during diabetes. Studies are warranted so as to check this perspective where the role of CALPAINS and its isoforms could find their way in combating diabetic pathogenicity.

\section{Deubiquitinases (DUBs)}

The cellular milieu also possesses a set of proteases called deubiquitinases which reverse the ubiquitin-dependent protein degradation. They work by opposing the function of ubiquitin E3 ligases. In a study, USP46 was identified as a deubiquitnase for both PHLPP isoforms leading to a significant potentiation of PHLPP function in the tumor cells (Li et al. 2013). Also, WDR48 and USP12 were identified as novel PHLPP1 deubiquitinating proteins. Similar to PHLPP1 function, they negatively regulate AKT activation and promote cellular apoptosis (Gangula \& Maddika 2013, Wei et al. 2014). On the other hand, USP1 was found to selectively regulate PHLPP1 half-life in lung carcinoma cells implicating a novel USP1-PHLPP1AKT signaling axis playing a major role in lung cancer cells in lung cancer progression (Zhiqiang et al. 2012). Essential studies are required to unravel more of these debiquitinases that probably exist to counter E3 ligases during hyperglycemia to influence PHLPP.

PHLPP mRNA translation is also regulated by miRNAs. Several different miRNAs target the 30-UTR of both PHLPP1 and PHLPP2. The 30 untranslated region (UTR) of PHLPP1 is targeted by miR-190. Metal toxicity results in increase of miR-190 levels, resulting in downregulation of PHLPP1 protein expression (Beezhold et al. 2011). In hepatocellular carcinoma (HCC), miR-331-3p targets both PHLPP isoforms and is highly expressed along with miR-3127 (Chang et al. 2014). miR-205 has been shown to target the 30 UTR of PHLPP2 and PTEN. Gliomas are marked with upregulated miR-93 levels, which inhibit PHLPP2, PTEN and FOXO3 expression (Cai et al. 2013). To summarize, strong evidence suggests miscellaneous regulators of PHLPP, and a lot more studies are required to completely unveil them.

\section{Post-translational modifications by PHLPP regulate the epigenome}

PHLPPs are known to regulate the epigenome by modulating histone acetylation and phosphorylation. Very recently, CYR1 (adenylate cyclase encoded in the Saccharomyces cerevisiae) exhibited PHLPP-associated

Published by Bioscientifica Ltd. 
phosphatase activity where its overexpression resulted in reduced phosphorylation of substrates including histone (H3) at Ser 10. CYR1 holds homology to PHLPP in comprising a leucine-rich repeat (LRR) segment and a Serine/Threonine PP2C phosphatase domain; however, it lacks the PH domain and C-terminal PDZ ligand of mammalian PHLPP. Thus, the ability of CYR1 to suppress histone phosphorylation is consistent with the studies of mammalian PHLPP where the LRR segments appear critical for its epigenetic function (Grzechnik et al. 2016). In mammalian systems, it was observed that loss of PHLPP results in enhanced phosphorylation and/or acetylation of the histones. PHLPP1 translocates only at promoters of the genes that are sensitive to PHLPP. This possibility proclaims that PHLPP directly modifies histones on these specific promoters (Reyes et al. 2014) Moreover, HDAC inhibitors regulate the expression of PHLPP1. A study demonstrated that HDAC3 upon association with PHLPP1 promoter region controls chondrocyte hypertrophy and matrix content by activating AKT through repressing PHLPP1 expression (Bradley et al. 2013). During chondriogenesis, stimulation with TGF $\beta$, a potent activator of chondrogenesis, causes HDAC3 association with the PHLPP1 promoter leading to decreased transcription of PHLPP1. Further, a study revealed that PHLPP1 expression was elevated in human patients with osteoarthritis due to a decrease in methylation of the PHLPP1 promoter (Bradley et al. 2016).

Further, in the context of insulin signaling, a very exciting study proclaims that PHLPP suppresses receptor tyrosine kinase (RTK) signaling output by epigenetic mechanisms. Nuclear-localized PHLPP suppresses histone phosphorylation and acetylation of diverse growth factor receptors, including the transcriptional downregulation of EGF receptor. By reducing RTK levels, PHLPP dampens the downstream signaling output of two major signaling pathways, the PI3 kinase/AKT and the Rat sarcoma (RAS)/ERK pathways. Therefore, this appears to reveal an additional role of PHLPPs upon insulin receptors during diabetes to check the downstream signaling cascades (Reyes et al. 2014).

\section{Role in other diseases}

PHLPP is now no longer just the 'hydrophobic motif' phosphatase. In addition to its tumor suppressive role, it has been found to be associated to hypoxic conditions observed during carcinomas and diabetic nephropathy. Hypoxia (during carcinoma) is associated with decreased
PHLPP expression (Wen et al. 2013). It mediates HIF1 $\alpha$ dependent tumorigenesis in colon cancer cells. Studies are required to assess this mechanism during diabetic hypoxic conditions. PHLPP extends its role in modulating the inflammatory molecules during gliomas. Loss of PHLPP1 is negatively associated to severity of tumor and inflammatory cytokines. Silencing of PHLPP1 improves the levels of inflammatory cytokines in glioma cells (Tenga et al. 2016). It has also been determined as a critical factor in influencing drug sensitivity under hypoxic conditions in colon cancer cells (Wen et al. 2013). Future studies shall inspect several PHLPP-associated molecular targets that would provide potentially promising novel therapeutic approach for multiple diseases.

\section{Concluding remarks and future perspectives}

There is a loss in insulin action due to gain in PHLPP function during diabetes. This makes PHLPP an important regulator of cellular mechanisms and thus warrants further studies to completely characterize the role of PHLPP in disease progression. The mechanism by which PHLPPs affect AKT isoforms and subsequent downstream substrates is incompletely understood. Studies have allowed the identification of interventions with several molecular factors from which it is apparent that PHLPP is tightly regulated and there exists a balance between several different processes that are responsible for maintaining redox signaling and cell survival. The amplitude of AKT activation under the mTOR/PHLPP regulon and the relative actions of the scaffolding proteins (SRPK1 and FKBP5) in regulating the proximity of enzyme (PHLPP) and substrates (AKT, PKC, MST1) influences the overall cellular response. PHLPP and its related signaling pathways, particularly PI3K/AKT, impact multiple metabolic parameters that include cellular homeostasis, insulin resistance, insulin secretion, pancreatic $\beta$-cell function, autophagy and programmed cell death. PHLPP is a critical component for a number of signaling pathways that involve phosphoinositide 3-kinase (PI3K), protein kinase B (AKT) and PKC. Advent in studies concerning PHLPP in diabetes is beginning to unveil the targets and upstream regulators of this phosphatase. It would be interesting to ascertain the interactions of the two PHLLP isoforms which share high homology in their activity domains yet differ in substrate specificity and spatio-temporal expression. Therefore, identification of molecules regulating its activity shall allow generation of specific target inhibitors or agonist molecules to prevent

Published by Bioscientifica Ltd 
the poor prognosis during insulin-resistant states. PHLPP therefore represents an exciting target to offer new clinical avenues for the treatment of T2D. Thus, underscoring the need to elucidate mechanisms that regulate the pathophysiology during diabetes through PHLPP function still remains to be fully understood. Future studies are directed to identify the delicate balance that PHLPP holds over cellular metabolism, and the impact of its diverse signaling pathways should endorse the translation of these targets into effective clinical regimens for diabetes.

\section{Declaration of interest}

The authors declare that there is no conflict of interest that could be perceived as prejudicing the impartiality of this review.

\section{Funding}

Financial assistance from CSIR Network Project-BSC 0106 to Kakkar P and Mathur A and from UGC to Pandey V K is highly acknowledged.

\section{Acknowledgement}

We are grateful to the Institutional Manuscript Review Committee of CSIRIITR for the review of the article.

\section{References}

Aghdam SY, Gurel Z, Ghaffarieh A, Sorenson CM \& Sheibani N 2013 High glucose and diabetes modulate cellular proteasome function. Implications in the Pathogenesis of Diabetes Complications 432 339-344. (doi:10.1016/j.bbrc.2013.01.101)

Aguayo A, Urrutia I, González-Frutos T, Martínez R, Martínez-Indart L, Castaño L \& Gaztambide S 2016 Prevalence of diabetes mellitus and impaired glucose metabolism in the adult population of the Basque Country, Spain. Diabetic Medicine 34 662-666. (doi:10.1111/ dme.13181)

Andreozzi F, Procopio C, Greco A, Mannino GC, Miele C, Raciti GA, Iadicicco C, Beguinot F, Pontiroli AE, Hribal ML, et al. 2011 Increased levels of the Akt-specific phosphatase PH domain leucine-rich repeat protein phosphatase (PHLPP)-1 in obese participants are associated with insulin resistance. Diabetologia 54 1879-1887. (doi:10.1007/ s00125-011-2116-6)

Ardestani A, Paroni F, Azizi Z, Kaur S, Khobragade V, Yuan T, Frogne T, Tao W, Oberholzer J, Pattou F, et al. 2014 MST1 is a novel regulator of apoptosis in pancreatic beta-cells. Nature Medicine 20 385-397. (doi:10.1038/nm.3482)

Arias E, Koga H, Diaz A, Mocholi E, Patel B \& Cuervo AM 2015 Lysosomal mTORC2/PHLPP1/Akt regulate chaperone-mediated autophagy. Molecular Cell 59 270-284. (doi:10.1016/j.molcel.2015.05.030)

Aviv Y \& Kirshenbaum LA 2010 Novel phosphatase PHLPP-1 regulates mitochondrial Akt activity and cardiac cell survival. Circulation Research 107 448-450. (doi:10.1161/CIRCRESAHA.110.225896)

Beezhold K, Liu J, Kan H, Meighan T, Castranova V, Xianglin S \& Chen F 2011 miR-190-mediated downregulation of PHLPP contributes to arsenic-induced Akt activation and carcinogenesis. Toxicological Sciences 123 411-420. (doi:10.1093/toxsci/kfr188)
Bodhini D, Radha V, Ghosh S, Sanapala KR, Majumder PP, Rao MR \& Mohan V 2011 Association of calpain 10 gene polymorphisms with type 2 diabetes mellitus in Southern Indians. Metabolism 60 681-688. (doi:10.1016/j.metabol.2010.07.001)

Borsting E, Patel SV, Declèves AE, Lee SJ, Rahman QM, Akira S, Satriano J, Sharma K, Vallon V \& Cunard R 2014 Tribbles homolog 3 attenuates mammalian target of rapamycin complex-2 signaling and inflammation in the diabetic kidney. Journals of the American Society of Nephrology 25 2067-2078. (doi:10.1681/ASN.2013070811)

Brognard J \& Newton AC 2008 PHLiPPing the switch on Akt and protein kinase C signaling. Trends in Endocrinology and Metabolism 19 223-230. (doi:10.1016/j.tem.2008.04.001)

Bradley EW, Carpio LR \& Westendorf JJ 2013 Histone deacetylase 3 suppression increases ph domain and leucine-rich repeat phosphatase (Phlpp)1 expression in chondrocytes to suppress Akt signaling and matrix secretion. Journal of Biological Chemistry $2889572-9582$. (doi:10.1074/jbc.M112.423723)

Bradley EW, Carpio LR, McGee-Lawrence ME, Castillejo Becerra C, Amanatullah DF, Ta LE, Otero M, Goldring MB, Kakar S \& Westendorf JJ 2016 Phlpp1 facilitates post-traumatic osteoarthritis and is induced by inflammation and promoter demethylation in human osteoarthritis. Osteoarthritis and Cartilage 24 1021-1018. (doi:10.1016/j.joca.2015.12.014)

Brognard J, Sierecki E, Gao T \& Newton AC 2007 PHLPP and a second isoform, PHLPP2, differentially attenuate the amplitude of Akt signaling by regulating distinct Akt isoforms. Molecular Cell $\mathbf{2 5}$ 917-931. (doi:10.1016/j.molcel.2007.02.017)

Cai J, Fang L, Huang Y, Li R, Yuan J, Yang Y, Zhu X, Chen B, Wu J \& Li M 2013 miR-205 targets PTEN and PHLPP2 to augment AKT signaling and drive malignant phenotypes in non-small cell lung cancer. Cancer Research 73 5402-5415. (doi:10.1158/0008-5472.CAN-13-0297)

Caricilli AM, Penteado E, de Abreu LL, Quaresma PG, Santos AC, Guadagnini D, Razolli D, Mittestainer FC, Carvalheira JB, Velloso LA, et al. 2012 Topiramate treatment improves hypothalamic insulin and leptin signaling and action and reduces obesity in mice. Endocrinology 153 4401-4411. (doi:10.1210/en.2012-1272)

Chang RM, Yang H, Fang F, Xu JF \& Yang LY 2014 MicroRNA-331-3p promotes proliferation and metastasis of hepatocellular carcinoma by targeting PH domain and leucine-rich repeat protein phosphatase. Hepatology 60 1251-1263. (doi:10.1002/hep.27221)

Copps KD \& White MF 2012 Regulation of insulin sensitivity by serine/ threonine phosphorylation of insulin receptor substrate proteins IRS1 and IRS2. Diabetologia 55 2565-2582. (doi:10.1007/s00125-012-2644-8)

Das R, Sebo Z, Pence L \& Dobens LL 2014 Drosophila tribbles antagonizes insulin signaling-mediated growth and metabolism via interactions with Akt kinase. PLOS ONE 9 e109530. (doi:10.1371/journal. pone.0109530)

Fetterman JL, Holbrook M, Westbrook DG, Brown JA, Feeley KP, BretónRomero R, Linder EA, Berk BD, Weisbrod RM, Widlansky ME, et al. 2016 Mitochondrial DNA damage and vascular function in patients with diabetes mellitus and atherosclerotic cardiovascular disease. Cardiovascular Diabetology 15 53. (doi:10.1186/s12933-016-0372-y)

Gangula NR \& Maddika S 2013 WD Repeat protein WDR48 in complex with deubiquitinase USP12 suppresses Akt-dependent cell survival signaling by stabilizing $\mathrm{PH}$ domain leucine-rich repeat protein phosphatase 1 (PHLPP1). Journal of Biological Chemistry $\mathbf{2 8 8}$ 34545-34554. (doi:10.1074/jbc.M113.503383)

Gao T, Furnari F \& Newton AC 2005 PHLPP: a phosphatase that directly dephosphorylates Akt, promotes apoptosis, and suppresses tumor growth. Molecular Cell 18 13-24 (doi:10.1016/j.molcel.2005.03.008)

Gerber PA \& Rutter GA 2017 The role of oxidative stress and hypoxia in pancreatic beta-cell dysfunction in diabetes mellitus. Antioxidants and Redox Signaling 26 501-518. (doi:10.1089/ars.2016.6755)

Grzechnik AT \& Newton AC 2016 PHLPPing through history: a decade in the life of PHLPP phosphatases. Biochemical Society Transactions 44 1675-1682. (doi:10.1042/BST20160170) 
Grzechnik AT, Petty E, Pillus L \& Newton AC 2016 Phosphatase activity of the fungal adenylate cyclase Cyr1, the yeast homologue of PHLPP. FASEB Journal 30 (1 Supplement) abstract 1141.1. (available at: http:// www.fasebj.org/content/30/1_Supplement/1141.1)

Guo L, Guo ZX, Gong HP, Shang YY, Zhong M, Zhang Y \& Zhang W 2015 Tribbles homolog 3 is induced by high glucose and associated with apoptosis in human endothelial cells. Molecular Medicine Reports 12 1963-1970. (doi:10.3892/mmr.2015.3576)

Hanssen MJ, Wierts R, Hoeks J, Gemmink A, Brans B, Mottaghy FM, Schrauwen P \& van Marken Lichtenbelt WD 2015 Glucose uptake in human brown adipose tissue is impaired upon fasting-induced insulin resistance. Diabetologia 58 586-595. (doi:10.1007/s00125-0143465-8)

He P, Yanda M, Anitha M, Srinivasan M \& Yun C 2012 Insulin activates intestinal NHE3 via IRBIT. FASEB Journal 26 (1 Supplement) abstract 1152.21. (available at: http://www.fasebj.org/content/26/1 Supplement/1152.21)

He P, Zhao L, Zhu L, Weinman EJ, De Giorgio R, Koval M, Srinivasan S \& Yun CC 2015 Restoration of $\mathrm{Na}+/ \mathrm{H}+$ exchanger NHE3-containing macrocomplexes ameliorates diabetes-associated fluid loss. Journal of Clinical Investigation 125 3519-3531. (doi:10.1172/JCI79552)

Heiss EH, Schachner D, Zimmermann K \& Dirsch VM 2013 Glucose availability is a decisive factor for Nrf2-mediated gene expression. Redox Biology 1 359-365. (doi:10.1016/j.redox.2013.06.001)

Holmström KM, Baird L, Zhang Y, Hargreaves I, Chalasani A, Land JM, Stanyer L, Yamamoto M, Dinkova-Kostova AT \& Abramov AY 2013 Nrf2 impacts cellular bioenergetics by controlling substrate availability for mitochondrial respiration. Biology Open 2 761-770. (doi:10.1242/bio.20134853)

Hribal ML, Mancuso E, Spiga R, Mannino GC, Fiorentino TV, Andreozzi F \& Sesti G 2016 PHLPP phosphatases as a therapeutic target in insulin resistance-related diseases. Expert Opinion on Therapeutic Targets 20 663-675. (doi:10.1517/14728222.2016.1130822)

Humphrey RK, Yu SM, Flores LE \& Jhala US 2010 Glucose regulates steady-state levels of PDX1 via the reciprocal actions of GSK3 and AKT kinases. Journal of Biological Chemistry 285 3406-3416. (doi:10.1074/jbc.M109.006734)

Hur KY, Jung HS \& Lee MS 2010 Role of autophagy in $\beta$-cell function and mass. Diabetes, Obesity and Metabolism 2 20-26. (doi:10.1111/j.14631326.2010.01278.x)

Hwang WM, Bak DH, Kim DH, Hong JY, Han SY, Park KY, Lim K \& Lim DM 2015 Attenuation of streptozotocin-induced pancreatic beta cell death in transgenic fat-1 mice via autophagy activation. Endocrinology and Metabolism [in press].

Jackson TC, Verrier JD, Drabek T, Janesko-Feldman K, Gillespie DG, Uray T, Dezfulian C, Clark RS, Bayir H, Jackson EK, et al. 2013 Pharmacological inhibition of pleckstrin homology domain leucinerich repeat protein phosphatase is neuroprotective: differential effects on astrocytes. Journal of Pharmacology and Experimental Therapeutics 347 516-528. (doi:10.1124/jpet.113.206888)

Jain AK \& Jaiswal AK 2007 GSK-3beta acts upstream of Fyn kinase in regulation of nuclear export and degradation of NF-E2 related factor 2. Journal of Biological Chemistry 282 16502-16510. (doi:10.1074/jbc. M611336200)

Kato M, Yuan H, Xu ZG, Lanting L, Li SL, Wang M, Hu MC, Reddy MA \& Natarajan R 2006 Role of the Akt/FoxO3a pathway in TGF- $\beta 1$ mediated mesangial cell dysfunction: a novel mechanism related to diabetic kidney disease. Journal of the American Society of Nephrology 17 3325-3335. (doi:10.1681/ASN.2006070754)

Kim K, Qiang L, Hayden MS, Sparling DP, Purcell NH \& Pajvani UB 2016 mTORC1-independent raptor prevents hepatic steatosis by stabilizing PHLPP2. Nature Communications 7 10255. (doi:10.1038/ ncomms10255)

Koga T, Suico MA, Shimasaki S, Watanabe E, Kai Y, Koyama K, Omachi K, Morino-Koga S, Sato T, Shuto T, et al. 2015 ER stress induces SIRT1 expression via the PI3K-Akt-GSK3 $\beta$ signaling pathway and promotes hepatocellular injury. Journal of Biological Chemistry 290 30366-30374. (doi:10.1074/jbc.m115.664169)

Li X, Liu J \& Gao T 2009 -TrCP-mediated ubiquitination and degradation of PHLPP1 are negatively regulated by Akt. Molecular and Cellular Biology 29 6192-6205. (doi:10.1128/MCB.00681-09)

Li X, Stevens PD, Yang H, Gulhati P, Wang W, Evers BM \& Gao T 2013 The deubiquitination enzyme USP46 functions as a tumor suppressor by controlling PHLPP-dependent attenuation of Akt signaling in colon cancer. Oncogene 32 471-478. (doi:10.1038/onc.2012.66)

Li X, Stevens PD, Liu J, Yang H, Wang W, Wang C, Zeng Z, Schmidt MD, Yang M, Lee EY, et al. 2014 PHLPP is a negative regulator of RAF1, which reduces colorectal cancer cell motility and prevents tumor progression in mice. Gastroenterology 146 1301-1312. (doi:10.1053/j. gastro.2014.02.003)

Li C, Ge Y, Peng A \& Gong R 2015 The redox sensitive glycogen synthase kinase $3 \beta$ suppresses the self-protective antioxidant response in podocytes upon oxidative glomerular injury. Oncotarget 6 39493-39506. (doi:10.18632/oncotarget.5117)

Li Y, Zhang T, Huang Q, Sun Y, Chang X, Zhang H, Zhu Y \& Han X 2016 Inhibition of tumor suppressor p53 preserves glycationserum induced pancreatic beta-cell demise. Endocrine 54 383-395. (doi:10.1007/s12020-016-0979-5)

Liu J, Stevens PD \& Gao T 2011 mTOR-dependent regulation of PHLPP expression controls the rapamycin sensitivity in cancer cells. Journal of Biological Chemistry 286 6510-6520. (doi:10.1074/jbc. M110.183087)

Liu H, Cao MM, Wang Y, Li LC, Zhu LB, Xie GY \& Li YB 2015 Endoplasmic reticulum stress is involved in the connection between inflammation and autophagy in type 2 diabetes. General and Comparative Endocrinology 210 124-129. (doi:10.1016/j. ygcen.2014.09.006)

Machado-Neto JA, Favaro P, Lazarini M, Costa FF, Olalla Saad ST \& Traina F 2011 Knockdown of insulin receptor substrate 1 reduces proliferation and downregulates Akt/mTOR and MAPK pathways in K562 cells. Biochimica et Biophysica Acta 1813 1404-1411. (doi:10.1016/j.bbamcr.2011.04.002)

Marinho R, Mekary RA, Muñoz VR, Gomes RJ, Pauli JR \& de Moura LP 2015 Regulation of hepatic TRB3/Akt interaction induced by physical exercise and its effect on the hepatic glucose production in an insulin resistance state. Diabetology and Metabolic Syndrome 767. (doi:10.1186/s13098-015-0064-x)

Mendoza MC \& Blenis J 2007 PHLPPing it off: phosphatases get in the Akt. Molecular Cell 25 798-800. (doi:10.1016/j.molcel.2007.03.007)

Miyamoto S, Purcell NH, Smith JM, Gao T, Whittaker R, Huang K, Castillo R, Glembotski CC, Sussman MA, Newton AC, et al. 2010 PHLPP-1 negatively regulates Akt activity and survival in the heart. Circulation Research 107 476-484. (doi:10.1161/CIRCRESAHA.109.215020)

Molina JR, Agarwal NK, Morales FC, Hayashi Y, Aldape KD, Cote G \& Georgescu MM 2012 PTEN, NHERF1 and PHLPP form a tumor suppressor network that is disabled in glioblastoma. Oncogene $\mathbf{3 1}$ 1264-1274. (doi:10.1038/onc.2011.324)

Nanditha A, Ma RCW, Ramachandran A, Snehalatha C, Chan JCN, Chia KS, Shaw JE \& Zimmet PZ 2016 Diabetes in Asia and the Pacific: implications for the global epidemic. Diabetes Care $39472-485$ (doi:10.2337/dc15-1536)

Ni R, Zheng D, Xiong S, Hill DJ, Sun T, Gardiner RB, Fan GC, Lu Y, Abel ED, Peter A, et al. 2016 Mitochondrial calpain-1 disrupts ATP synthase and induces superoxide generation in type 1 diabetic hearts: a novel mechanism contributing to diabetic cardiomyopathy. Diabetes $\mathbf{6 5}$ 255-268. (doi:10.2337/db15-0963)

Ohoka N, Yoshii S, Hattori T, Onozaki K \& Hayashi H 2005 TRB3, a novel ER stress-inducible gene, is induced via ATF4-CHOP pathway and is involved in cell death. EMBO Journal 24 1243-1255. (doi:10.1038/ sj.emboj.7600596) http://joe.endocrinology-journals.org

DOI: 10.1530/JOE-17-0081
๑) 2017 Society for Endocrinology Printed in Great Britain 
O'Neill AK, Niederst MJ \& Newton AC 2013 Suppression of survival signalling pathways by the phosphatase PHLPP. FEBS Journal $\mathbf{2 8 0}$ 572-583. (doi:10.1111/j.1742-4658.2012.08537.x)

Pal A, Barber TM, de Bunt MV, Rudge SA, Zhang Q, Lachlan KL, Cooper NS, Linden H, Levy JC, Wakelam MJO, et al. 2013 PTEN mutations as a cause of constitutive insulin sensitivity and obesity in human beings. Lancet 381 S13. (doi:10.1016/S01406736(13)60453-5)

Pei H, Li L, Fridley BL, Jenkins GD, Kalari KR, Lingle W, Petersen G, Lou Z \& Wang L 2009 FKBP51 affects cancer cell response to chemotherapy by negatively regulating Akt. Cancer Cell 16 259-266. (doi:10.1016/j. ccr.2009.07.016)

Peiris H, Duffield MD, Fadista J, Jessup CF, Kashmir V, Genders AJ, McGee SL, Martin AM, Saiedi M, Morton N, et al. 2016 A syntenic cross species aneuploidy genetic screen links RCAN1 expression to $\beta$-cell mitochondrial dysfunction in type 2 diabetes. PLoS Genetics 12 e1006033. (doi:10.1371/journal.pgen.1006033)

Pereira MJ, Palming J, Svensson MK, Rizell M, Dalenbäck J, Hammar M, Fall T, Sidibeh CO, Svensson PA \& Eriksson JW 2014 FKBP5 expression in human adipose tissue increases following dexamethasone exposure and is associated with insulin resistance. Metabolism 63 1198-1208. (doi:10.1016/j.metabol.2014.05.015)

Qiao M, Wang Y, Xu X, Lu J, Dong Y, Tao W, Stein J, Stein GS, Iglehart JD, Shi Q, et al. 2010 Mst1 is an interacting protein that mediates PHLPPs' induced apoptosis. Molecular Cell 38 512-523. (doi:10.1016/j. molcel.2010.03.017)

Quan W, Lim YM \& Lee MS 2012 Role of autophagy in diabetes and endoplasmic reticulum stress of pancreatic $\beta$-cells. Experimental and Molecular Medicine 44 81-88. (doi:10.3858/emm.2012.44.2.030)

Rajala A, Gupta VK, Anderson RE \& Rajala RV 2013 Light activation of the insulin receptor regulates mitochondrial hexokinase: a possible mechanism of retinal neuroprotection. Mitochondrion 13 566-576. (doi:10.1016/j.mito.2013.08.005)

Reyes G, Niederst M, Cohen-Katsenelson K, Stender JD, Kunkel MT, Chen M, Brognard J, Sierecki E, Gao T, Nowak DG, et al. 2014 Pleckstrin homology domain leucine-rich repeat protein phosphatases set the amplitude of receptor tyrosine kinase output. PNAS 111 E3957-E3965. (doi:10.1073/pnas.1404221111)

Rizvi F, Shukla S \& Kakkar P 2014 Essential role of PH domain and leucine-rich repeat protein phosphatase 2 in Nrf2 suppression via modulation of Akt/GSK3 $\beta /$ Fyn kinase axis during oxidative hepatocellular toxicity. Cell Death and Disease 27 e1153. (doi:10.1038/ cddis.2014.118)

Roberts DJ \& Miyamoto S 2015 Hexokinase II integrates energy metabolism and cellular protection: Akting on mitochondria and TORCing to autophagy. Cell Death Differentiation 22 248-257. (doi:10.1038/cdd.2014.173)

Roberts DJ, Tan-Sah VP, Smith JM \& Miyamoto S 2013 Akt phosphorylates HK-II at Thr-473 and increases mitochondrial HK-II association to protect cardiomyocytes. Journal of Biological Chemistry 288 23798-23806. (doi:10.1074/jbc.M113.482026)

Sakai K, Matsumoto K, Nishikawa T, Suefuji M, Nakamaru K, Hirashima Y, Kawashima J, Shirotani T, Ichinose K, Brownlee M, et al. 2003 Mitochondrial reactive oxygen species reduce insulin secretion by pancreatic $\beta$-cells. Biochemical and Biophysical Research Communications 300 216-222. (doi:10.1016/S0006-291X(02)02832-2)

Schultze SM, Hemmings BA, Niessen M \& Tschopp O 2012 PI3K/ AKT, MAPK and AMPK signalling: protein kinases in glucose homeostasis. Expert Reviews in Molecular Medicine 14 e1. (doi:10.1017/ S1462399411002109)

Senapedis WT, Kennedy CJ, Boyle PM \& Silver PA 2011 Whole genome siRNA cell-based screen links mitochondria to Akt signaling network through uncoupling of electron transport chain. Molecular Biology of the Cell 22 1791-1805. (doi:10.1091/mbc.E10-10-0854)

Shang G, Tang X, Gao P, Guo F, Liu H, Zhao Z, Chen Q, Jiang T, Zhang N \& Li H 2015 Sulforaphane attenuation of experimental diabetic nephropathy involves GSK-3 beta/Fyn/Nrf2 signaling pathway. Journal of Nutritional Biochemistry 26 596-606. (doi:10.1016/j. jnutbio.2014.12.008)

Shimizu K, Okada M, Nagai K \& Fukada Y 2003 Suprachiasmatic nucleus circadian oscillatory protein, a novel binding partner of K-Ras in the membrane rafts, negatively regulates MAPK pathway. Journal of Biological Chemistry 278 14920-14925. (doi:10.1074/jbc.M213214200)

Shimizu K, Mackenziebc SM \& Storm DR 2010 SCOP/PHLPP and its functional role in the brain. Molecular BioSystems 6 38-43. (doi:10.1039/B911410F)

Sierecki E \& Newton AC 2014 Biochemical characterization of the phosphatase domain of the tumor suppressor PH domain leucine-rich repeat protein phosphatase. Biochemistry 53 3971-3981. (doi:10.1021/ bi500428j)

Sierecki E, Sinko W, McCammon JA \& Newton AC 2010 Discovery of small molecule inhibitors of the $\mathrm{PH}$ domain leucine-rich repeat protein phosphatase (PHLPP) by chemical and virtual screening. Journal of Medicinal Chemistry 53 6899-6911. (doi:10.1021/ jm100331d)

Smith MA, Covington MD \& Schnellmann G 2012 Loss of calpain 10 causes mitochondrial dysfunction during chronic hyperglycemia. Archives of Biochemistry and Biophysics 523 161-168. (doi:10.1016/j. abb.2012.04.020)

Song H, Mak KK, Topol L, Yun K, Hu J, Garrett L, Chen Y, Park O, Chang J, Simpson RM, et al. 2010 Mammalian Mst1 and Mst2 kinases play essential roles in organ size control and tumor suppression. PNAS 107 1431-1436. (doi:10.1073/pnas.0911409107)

Tasset I \& Cuervo AM 2016 Role of chaperone-mediated autophagy in metabolism. FEBS Journal 283 2403-2413. (doi:10.1111/febs.13677)

Tenga DC, Sunb J, Anc YQ, Hud ZH, Liue P, Mae YC, Hane B \& ShieY 2016 Role of PHLPP1 in inflammation response: Its loss contributes to gliomas development and progression. International Immunopharmacology 34 229-234. (doi:10.1016/j. intimp.2016.02.034)

Wang RC, Wei Y, An Z, Zou Z, Xiao G, Bhagat G, White M, Reichelt J \& Levine B 2012 Akt-mediated regulation of autophagy and tumorigenesis through beclin 1 phosphorylation. Science $\mathbf{3 3 8}$ 956-959. (doi:10.1126/science.1225967)

Wang P, Zhou Z, Hu A, Ponte de Albuquerque C, ZhouY, Hong L, Sierecki E, Ajiro M, Kruhlak M, Harris C, et al. 2014 Both decreased and increased SRPK1 levels promote cancer by interfering with PHLPPmediated dephosphorylation of Akt. Molecular Cell 54 378-391. (doi:10.1016/j.molcel.2014.03.007)

Warfel NA \& Newton AC 2012 Pleckstrin homology domain leucine-rich repeat protein phosphatase (PHLPP): a new player in cell signaling. Journal of Biological Chemistry 287 3610-3616. (doi:10.1074/jbc. R111.318675)

Warfel NA, Niederst M, Stevens MW, Brennan PM, Frame MC \& Newton AC 2011 Mislocalization of the E3 ligase, $\beta$-transducin repeatcontaining protein 1 ( $\beta$-TrCP1), in glioblastoma uncouples negative feedback between the pleckstrin homology domain leucine-rich repeat protein phosphatase 1 (PHLPP1) and Akt. Journal of Biological Chemistry 286 19777-19788. (doi:10.1074/jbc.M111.237081)

Wei XE, Zhang FY, Wang K, Zhang QX \& Rong LQ 2014 Assembly of the FKBP51-PHLPP2-AKT signaling complex in cerebral ischemia/ reperfusion injury in rats. Brain Research 1566 60-68. (doi:10.1016/j. brainres.2014.04.009)

Wen YA, Stevens PD, Gasser ML, Andrei R \& Gao T 2013 Downregulation of PHLPP expression contributes to hypoxia-induced resistance to chemotherapy in colon cancer cells. Molecular and Cellular Biology 33 4594-4605. (doi:10.1128/MCB.00695-13)

Winnay JN, Solheim MH, Dirice E, Sakaguchi M, Noh HL, Kang HJ, Takahashi H, Chudasama KK, Kim JK, Molven A, et al. 2016 PI3kinase mutation linked to insulin and growth factor resistance in vivo. Journal of Clinical Investigation 126 1401-1412. (doi:10.1172/ JCI84005) 
Xiaopeng X, Wen YA, Mitov MI, Oaks MC, Miyamoto S \& Gao T 2017 PHLPP regulates hexokinase 2-dependent glucose metabolism in colon cancer cells. Cell Death Discovery 3 16103. (doi:10.1038/ cddiscovery.2016.103)

Xiao L, Chen D, Hu P, Wu J, Liu W, Zhao Y, Cao M, Fang Y, Bi W, Zheng Z, et al. 2011 The c-Abl-MST1 signaling pathway mediates oxidative stress-induced neuronal cell death. Journal of Neuroscience $\mathbf{3 1}$ 9611-9619. (doi:10.1523/JNEUROSCI.0035-11.2011)

Xing Y, Sun W, Wang Y, Gao F \& Ma H 2016 Mutual inhibition of insulin signaling and PHLPP-1 determines cardioprotective efficiency of Akt in aged heart. Aging 8 873-888. (doi:10.18632/aging.100933)

Xiong X, Li X, Wen YA \& Gao T 2016 Pleckstrin homology (PH) domain leucine-rich repeat protein phosphatase controls cell polarity by negatively regulating the activity of atypical protein kinase C. Journal of Biological Chemistry 291 25167-25178. (doi:10.1074/jbc. M116.740639)
Yang JY, Yeh HY, Lin K \& Wang PH 2009 Insulin stimulates Akt translocation to mitochondria: Implications on dysregulation of mitochondrial oxidative phosphorylation in diabetic myocardium. Journal of Molecular and Cellular Cardiology 46 919-926. (doi:10.1016/j. yjmcc.2009.02.015)

Yang JY, Deng W, Chen Y, Fan W, Baldwin KM, Jope RS, Wallace DC \& Wang PH 2013 Impaired translocation and activation of mitochondrial Akt1 mitigated mitochondrial oxidative phosphorylation Complex V activity in diabetic myocardium. Journal of Molecular and Cellular Cardiology 59 165-175. (doi:10.1016/j. yjmcc.2013.08.001)

Zhiqiang Z, Qinghui Y, Yongqiang Z, Jian Z, Xin Z, Haiying M \& Yuepeng G 2012 USP1 regulates AKT phosphorylation by modulating the stability of PHLPP1 in lung cancer cells. Journal of Cancer Research and Clinical Oncology 138 1231-1238. (doi:10.1007/ s00432-012-1193-3)

Received in final form 22 March 2017

Accepted 20 April 2017

Accepted Preprint published online 20 April 2017
(C) 2017 Society for Endocrinology Printed in Great Britain
Published by Bioscientifica Ltd 